\title{
FAKTOR-FAKTOR YANG MEMPENGARUHI KEPATUHAN WAJIB PAJAK BADAN
}

\author{
Fhatur Akbar* dan Muhammad Nuryatno \\ Program Studi Akuntansi, Fakultas Ekonomi dan Bisnis, Universitas Trisakti \\ Jl. Kyai Tapa No. 1 Grogol, Jakarta, Indonesia* \\ Email Koresponden: fhaturakbar@rocketmail.com
}

167

Diterima:

24 September 2018

Direvisi:

28 Oktober 2018

Disetujui:

29 Oktober 2018

Artikel ini tersedia di website: http:// ejournal.umm.ac.id/ index.php/jrak

Doi: $10.22219 /$ jrak.v8i2.36

\section{PENDAHULUAN}

Pajak merupakan iuran wajib yang harus dibayarkan oleh badan atau orang pribadi kepada negara yang diatur oleh negara berdasarkan undang-undang kepada masyarakat dan bersifat memaksa, dan terutang yang wajib dibayar dengan tidak mendapatkan imbalan secara langsung, dan hasilnya akan digunakan untuk membiayai penyelenggaraan pemerintahan negara dan pembangunan (Siahaan, 2013: 7). Pajak merupakan salah satu sumber penerimaan negara yang sangat penting bagi terselenggaranya pemerintahan dan peningkatan pembangunan negara. Kontribusi dari masyarakat dalam membayar pajak sangat dibutuhkan demi kemajuan negara.

Direktrorat Jendral Pajak mencatat sebanyak 325 ribu wajib pajak badan telah melaporkan Surat Pemberitahuan (SPT) tahunan untuk tahun pajak 2017 sampai hari Rabu (18/4). Artinya baru sekitar 23\% SPT yang telah dilaporkan dari total 1,4 juta wajib pajak badan. Direktur Penyuluhan, Pelayanan dan Humas Ditjen Pajak Hestu Yoga Saksama menyatakan sebagian besar wajib pajak badan memiliki batas waktu pelaporan pada 30 April 2018 sesuai periode buku. Wajib Pajak Badan masih dapat melaporkan SPT walaupun telah melebihi batas waktu dengan membayar denda administrative sebesar Rp 1 juta. Namun, apabila terlambat membayar maka wajib pajak akan dikenakan denda sebesar $2 \%$ per bulan dari pajak terhutang. Wajib pajak badan dapat melaporkan SPT secara langsung, menggunakan pos, jasa kurir, jasa ekspedisi, dan secara elektronik. Walaupun mayoritas wajib pajak badan akan menempuh batas waktu 30 April 2018, hal ini tidak akan menambah jam ataupun hari layanan di kantor pajak

Penelitian terdahulu meneliti mengenai pengetahuan dan pemahaman wajib pajak, kesadaran wajib pajak, sanksi perpajakan, dan penghindaran pajak. Atas acuan penelitian sebelumnya, maka peneliti akan meneliti dengan memilih sampel responden wajib pajak badan yang terdaftar di KPP Gambir Empat pada tahun 2018.

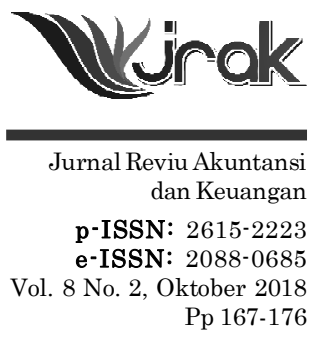


Faktor-

Faktor yang

Mempengaruhi.

\section{8}

Gambar 1 Model Penelitian

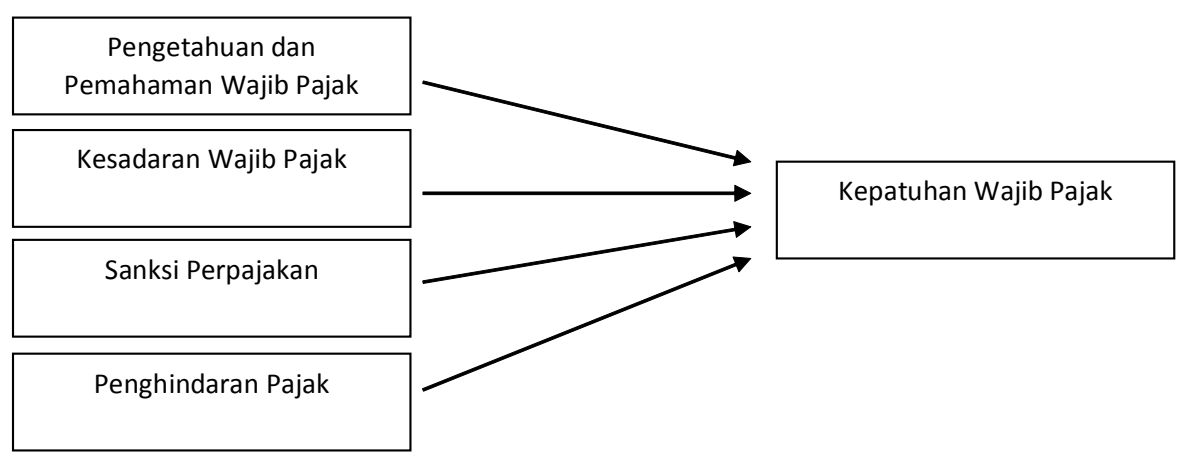

\section{METODE PENELITIAN}

Penelitian ini dirancang guna memperjelas kajian hipotesis dengan melakukan pengujian variabel pengaruh pengetahuan dan pemahaman wajib pajak, kesadaran wajib pajak, sanksi perpajakan, dan penghindaran pajak terhadap kepatuhan wajib pajak badan

\begin{tabular}{|c|c|c|c|}
\hline Variabel & Indikator Pertanyaan & $\begin{array}{c}\text { Butir } \\
\text { Pertanyaan }\end{array}$ & $\begin{array}{c}\text { Skala } \\
\text { Pengukuran }\end{array}$ \\
\hline \multirow[t]{3}{*}{$\begin{array}{l}\text { Pengetahuan } \\
\text { dan } \\
\text { Pemahaman } \\
\text { Wajib Pajak }\end{array}$} & $\begin{array}{l}\text { Wajib Pajak yang sudah memiliki } \\
\text { penghasilan harus mendaftarkan } \\
\text { diri untuk memperoleh NPWP } \\
\text { (Nomor Pokok Wajib Pajak) }\end{array}$ & 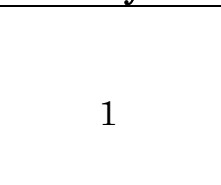 & $\begin{array}{l}\text { Skala } \\
\text { Interval }\end{array}$ \\
\hline & $\begin{array}{l}\text { Masyarakat memahami fungsi dan } \\
\text { manfaat pajak dengan baik } \\
\text { Pengetahuan dan pemahaman wajib } \\
\text { pajak didapat dari sosialisasi yang } \\
\text { diadakan di KPP } \\
\text { Sistem yang berlaku pada saat ini } \\
\text { yaitu self assessment }\end{array}$ & 2 & \\
\hline & $\begin{array}{l}\text { Mengetahui jumlah pajak yang } \\
\text { ditanggung }\end{array}$ & 5 & \\
\hline \multirow[t]{3}{*}{$\begin{array}{l}\text { Kesadaran } \\
\text { Wajib Pajak }\end{array}$} & $\begin{array}{l}\text { Pembayaran pajak yang dilakukan } \\
\text { wajib pajak merupakan wujud } \\
\text { partisipasi dalam menunjang } \\
\text { pembangunan negara } \\
\text { Pembayaran pajak yang dilakukan } \\
\text { oleh wajib pajak akan merugikan } \\
\text { negara apabila tidak dilakukan }\end{array}$ & 1 & $\begin{array}{l}\text { Skala } \\
\text { Interval }\end{array}$ \\
\hline & $\begin{array}{l}\text { Sosialisasi yang dilakukan tentang } \\
\text { perpajakan akan meningkatkan } \\
\text { kesadaran wajib pajak dalam } \\
\text { melaksanakan kewajibannya }\end{array}$ & 3 & \\
\hline & $\begin{array}{l}\text { Sistem yang berlaku sekarang } \\
\text { memudahkan para wajib pajak } \\
\text { dalam melakukan kewajibannya }\end{array}$ & 4 & \\
\hline
\end{tabular}

Tabel 1. Operasionalisasi Variable dan Pengukurannya
Wajib Pajak yang sudah memiliki penghasilan harus mendaftarkan diri untuk memperoleh NPWP

Masyarakat memahami fungsi dan nfaat pajak dengan baik

Pengetahuan dan pemahaman wajib pajak didapat dari sosialisasi yang Sistem yang berlaku pada saat ini yaitu self assessment

Mengetahui jumlah pajak yang Pembayaran pajak yang dilakukan wajib pajak merupakan wujud pembangunan negara Pembayaran pajak yang dilakukan oleh wajib pajak akan merugikan

Sosialisasi yang dilakukan tentang perpajakan akan meningkatkan kesadaran wajib pajak dalam Sistem yang berlaku sekarang memudahkan para wajib pajak 
Yang terdaftar di KPP PRATAMA Jakarta Gambir Empat. Pengujian hipotesis ini merupakan hubungan yang dirancang secara logis diantara dua variabel atau lebih yang diungkapkan dalam bentuk pertanyaan yang dapat diuji

\begin{tabular}{|c|c|c|c|}
\hline \multirow[t]{2}{*}{ Sanksi Perpajakan } & $\begin{array}{l}\text { Sanksi Perpajakan diperlukan } \\
\text { agar tidak terjadi pelanggaran } \\
\text { pajak } \\
\text { Sanksi Perpajakan yang } \\
\text { diatur sudah menjadikan } \\
\text { wajib pajak patuh dalam } \\
\text { melaksanakan } \\
\text { Sanksi yang dikenakan } \\
\text { kepada wajib pajak tidak } \\
\text { dapat dinegosiasikan }\end{array}$ & 3 & $\begin{array}{c}\text { Skala } \\
\text { Interval }\end{array}$ \\
\hline & $\begin{array}{l}\text { Sanksi administrasi berupa } \\
\text { denda sebesar } 50 \% \text { dari pajak } \\
\text { yang kurang dibayar, apabila } \\
\text { SPT diisi dengan tidak benar }\end{array}$ & 4 & \\
\hline \multirow[t]{2}{*}{$\begin{array}{l}\text { Penghindaran } \\
\text { Pajak }\end{array}$} & $\begin{array}{l}\text { Penghindaran Pajak etis } \\
\text { dilakukan apabila tarif pajak } \\
\text { yang dikenakan terlalu tinggi }\end{array}$ & 1 & $\begin{array}{c}\text { Skala } \\
\text { Interval }\end{array}$ \\
\hline & $\begin{array}{l}\text { Penghindaran Pajak etis } \\
\text { dilakukan apabila para } \\
\text { masyarakat tidak merasakan } \\
\text { manfaat dari pajak yang } \\
\text { disetor } \\
\text { Penghindaran Pajak etis } \\
\text { terjadi apabila wajib pajak } \\
\text { didiskriminasi dalam } \\
\text { perpajakan }\end{array}$ & 3 & \\
\hline \multirow[t]{2}{*}{$\begin{array}{l}\text { Kepatuhan Wajib } \\
\text { Pajak }\end{array}$} & $\begin{array}{l}\text { Wajib Pajak bersedia dalam } \\
\text { melaksanakan kegiatan } \\
\text { perpajakannya }\end{array}$ & 1 & $\begin{array}{c}\text { Skala } \\
\text { Interval }\end{array}$ \\
\hline & $\begin{array}{l}\text { Wajib Pajak harus membayar } \\
\text { kewajibannya dengan } \\
\text { perhitungan yang benar } \\
\text { Wajib Pajak membayar } \\
\text { kekurangan dari } \\
\text { tanggungannya sebelum } \\
\text { dilakukan pemeriksaan }\end{array}$ & 3 & \\
\hline
\end{tabular}

\section{Model Regresi Penelitian}

$$
\operatorname{Logit}(p)=\alpha+\beta 1 . X_{1}+\beta 2 . X_{2}+\beta 3 X_{3}+\beta 4 X_{4}+€
$$

Keterangan:

$\alpha$ : konstanta

$€ \quad=$ error

$\mathrm{y}(\mathrm{p})=$ perbandingan antara P-Score dan Z-Score.

$\mathrm{X} 1$ = Pengetahuan dan Pemahaman Wajib Pajak

$\mathrm{X} 2=$ Kesadaran Wajib Pajak

X3 = Sanksi Perpajakan

$\mathrm{X} 4=$ Penghindaran Pajak 
Faktor-

Faktor yang

Mempengaruhi..

170

Tabel 2.

Responden

berdasarkan Jenis

Usaha

Tabel 3.

Responden

Berdasarkan Lama

Usaha

Tabel 4.

Responden

Berdasarkan Omset

Pertahun

Hasil Uji Statistik

Deskriptif

\section{HASIL DAN PEMBAHASAN}

Penelitian ini menggunakan data primer, teknik pengumpulan data dalam penelitian ini kuesioner yang dibagikan kepada wajib pajak badan di KPP Pratama Gambir Empat.

\begin{tabular}{lcc}
\hline \multirow{2}{*}{ Jenis Usaha } & \multicolumn{2}{c}{ Jumlah Responden } \\
\cline { 2 - 3 } \multicolumn{1}{c}{ Manufaktur } & Frekuensi & Persentase (\%) \\
\hline Perbankan & 36 & 28.8 \\
Perdagangan dan Jasa & 64 & 51.2 \\
Lainnya & 19 & 15.2 \\
Jumlah & 6 & 4.8 \\
\hline
\end{tabular}

\begin{tabular}{ccc}
\hline \multirow{2}{*}{ Umur } & \multicolumn{2}{c}{ Jumlah Responden } \\
\cline { 2 - 3 }$<1$ tahun & Frekuensi & Persentase (\%) \\
\hline 1-5 tahun & 24 & 19.2 \\
6-10 tahun & 74 & 59.2 \\
$>$ 10 tahun & 11 & 8.8 \\
Jumlah & 16 & 12.8 \\
\hline
\end{tabular}

\begin{tabular}{ccc}
\hline \multirow{2}{*}{ Omset Pertahun } & \multicolumn{2}{c}{ Jumlah Responden } \\
\cline { 2 - 3 }$<4,8$ miliar & Frekuensi & \\
\cline { 2 - 3 }$>4,8$ miliar & 39 & $<4,8$ miliar \\
Jumlah & 86 & $>4,8$ miliar \\
\hline
\end{tabular}

\section{Statistik Deskriptif}

\begin{tabular}{lccccc}
\hline \multicolumn{1}{c}{ Variabel } & N & Minimum & Maximum & Mean & $\begin{array}{c}\text { Std. } \\
\text { Deviasi }\end{array}$ \\
\hline Pengetahuan dan & 125 & 2 & 5 & 3.62 & 0.78 \\
Pemahaman Wajib Pajak & & & & & \\
Kesadaran Wajib Pajak & 125 & 1 & 5 & 3.57 & 0.83 \\
$\quad$ Sanksi Pajakan & 125 & 1 & 5 & 3.36 & 0.87 \\
Penghindaran Pajak & 125 & 1 & 5 & 3.43 & 0.77 \\
Kepatuhan Wajib Pajak & 125 & 1 & 5 & 3.61 & 0.74 \\
\hline
\end{tabular}

Berdasarkan tabel diatas dapat dilihat nilai terendah, tertinggi, dan ratarata dari kepatuhan wajib pajak, penerapan modernisasi sistem administrasi perpajakan, pemahaman peraturan perpajakan, penerapan sanksi perpajakan, kualitas pelayanan fiskus dengan jumlah sampel sebanyak 100 wajib pajak badan di KPP Pratama Gambir Empat. 


\section{Uji Validitas}

Berdasarkan tabel 6 maka dapat disimpulkan bahwa variabel kepatuhan wajib pajak, modernisasi sistem administrasi perpajakan, pemahaman peraturan perpajakan, sanksi perpajakan dan kualitas perlayanan fiskus valid.

\begin{tabular}{lccc}
\hline \multicolumn{1}{c}{ Variabel } & KMO & Kriteria & Keputusan \\
\hline Pengetahuan dan & 0.778 & 0.5 & Valid \\
Pemahaman Wajib Pajak & & & \\
Kesadaran Wajib Pajak & 0.768 & 0.5 & Valid \\
Sanksi Perpajakan & 0.650 & 0.5 & Valid \\
Penghindaran Pajak & 0.742 & 0.5 & Valid \\
\hline
\end{tabular}

\section{Uji Reliabilitas}

\begin{tabular}{lccc}
\hline \multicolumn{1}{c}{ Variabel } & Cronbach Alpha & Kriteria & Keterangan \\
\hline Pengetahuan dan & 0.878 & 0.60 & Reliabel \\
Pemahaman Wajib Pajak & & & \\
Kesadaran Wajib Pajak & 0.833 & 0.60 & Reliabel \\
Sanksi Pajak & 0.666 & 0.60 & Reliabel \\
Penghindaran Pajak & 0.750 & 0.60 & Reliabel \\
Kepatuhan Wajib Pajak & 0.806 & 0.60 & Reliabel \\
\hline
\end{tabular}

Berdasarkan tabel diatas, dapat diketahui bahwa setiap pertanyaan digunakan dalam penelitian untuk mengukur variabel modernisasi sistem administrasi perpajakan, pemahaman peraturan perpajakan, sanksi perpajakan, kualitas pelayanan fiskus dan kepatuhan wajib pajak masing-masing memiliki nilai Cronbach's Coefficient Alpha> 0.6. Dengan demikian, seluruh pertanyaan dalam variabel-variabel tersebut adalah konsisten dan dapat diandalkan (reliabel)

\section{Uji Regresi Berganda}

Berdasarkan hasil analisis diatas dapat dijelaskan melalui model regresi sebagai berikut:

$\mathrm{Y}=3.648+0.313 \mathrm{X}_{1}+0.174 \mathrm{X}_{2}+0.219 \mathrm{X}_{3}+0.242 \mathrm{X}_{4}+\varepsilon$

Dari persamaan regresi tersebut dapat dijelaskan sebagai berikut:

1) Konstanta $=3.648$, artinya jika variabel pengetahuan dan pemahaman wajib pajak, kesadaran wajib pajak, sanksi pajak dan penghindaran pajak

\begin{tabular}{lcc}
\hline \multirow{2}{*}{ Model } & \multicolumn{2}{c}{ Unstandardized Coefficients } \\
\cline { 2 - 3 } & B & Std. Error \\
\hline (Constant) & 3.648 & 1.169 \\
X1 & 0.313 & 0.074 \\
X2 & 0.174 & 0.083 \\
X3 & 0.219 & 0.082 \\
X4 & 0.242 & 0.093 \\
\hline
\end{tabular}

Tabel 7.

Uji Reliabilitas

Tabel 6.

Uji Validitas

-

Tabel 8.

Uji Analisis Regresi Berganda 
Faktor-

Faktor yang

Mempengaruhi.

172 dianggap sama dengan nol, maka variabel kepatuhan wajib pajak mempunyai nilai 3.648.

2) Koefisien pengetahuan dan pemahaman wajib pajak $=0.313$, artinya jika variabel pengetahuan dan pemahaman wajib pajak mengalami kenaikan sebesar 1 satuan sedangkan variabel lain dianggap konstan, maka variabel dependen yaitu kepatuhan wajib pajak akan mengalami kenaikan sebesar 0.313 .

3) Koefisien kesadaran wajib pajak $=0.174$, artinya jika variabel kesadaran wajib pajak mengalami kenaikan sebesar 1 satuan sedangkan variabel lain dianggap konstan, maka variabel dependen yaitu kepatuhan wajib pajak akan mengalami kenaikan sebesar 0.174 .

4) Koefisien sanksi pajak $=0.219$, artinya jika variabel sanksi pajak mengalami kenaikan sebesar 1 satuan sedangkan variabel lain dianggap konstan, maka variabel dependen yaitu kepatuhan wajib pajak akan mengalami kenaikan sebesar 0.219 .

5) Koefisien penghindaran pajak $=0.242$, artinya jika variabel penghindaran pajak mengalami kenaikan sebesar 1 satuan sedangkan variabel lain dianggap konstan, maka variabel dependen yaitu kepatuhan wajib pajak akan mengalami kenaikan sebesar 0.242 .

\section{Uji Hipotesis}

\begin{tabular}{lrrrrr}
\hline \multicolumn{1}{c}{ Modal } & $\begin{array}{l}\text { Sum of } \\
\text { Square }\end{array}$ & \multicolumn{1}{c}{ Df } & $\begin{array}{c}\text { Mean } \\
\text { Square }\end{array}$ & F & \multicolumn{1}{c}{ Sig. } \\
\hline Regression & 546.666 & 4 & 136.667 & 40.006 & $.000^{\mathrm{b}}$ \\
Residual & 409.942 & 120 & 3.416 & & \\
Total & 956.608 & 124 & & & \\
\hline
\end{tabular}

Berdasarkan Tabel 9 diperoleh nilai $\mathrm{F}$ hitung sebesar 40.006 dengan taraf signifikansi sebesar 0,000. Ini menunjukkan bahwa taraf signifikansi $\mathrm{F}$ hitung lebih kecil dari nilai tingkat signifikansi 0,05 dan F hitung $>\mathrm{F}$ tabel atau 40.006 > 2.45. Artinya bahwa variabel pengetahuan dan pemahaman wajib pajak, kesadaran wajib pajak, sanksi perpajakan dan penghindaran pajak secara bersama-sama mempunyai pengaruh yang signifikan terhadap kepatuhan wajib pajak.

\begin{tabular}{|c|c|c|}
\hline Model & $\mathrm{t}$ & Sig. \\
\hline (Constant) & 3.120 & .002 \\
\hline $\mathrm{X} 1$ & 4.214 & .000 \\
\hline $\mathrm{X} 2$ & 2.086 & .039 \\
\hline $\mathrm{X} 3$ & 2.665 & .009 \\
\hline $\mathrm{X} 4$ & 2.606 & .010 \\
\hline
\end{tabular}

Berdasarkan tabel, hasil pengujian secara parsial adalah sebagai berikut:

1) Berdasarkan hasil uji t (parsial) pada model regresi, nilai signifikansi variabel pengetahuan dan pemahaman wajib pajak sebesar $0.000<0.05$ (taraf signifikansi 5\%). Selain itu dapat dilihat juga dari hasil perbandingan antara $t$ hitung dan t tabel yang menunjukkan nilai $t_{\text {hitung }}$ sebesar 4.214, sedangkan $\mathrm{t}_{\text {tabel }}$ sebesar 1.65765. Dari hasil tersebut terlihat bahwa $\mathrm{t}_{\text {hitung }}>\mathrm{t}_{\text {tabel }}$ yaitu 4.214 $>1.65765$ dan nilai signifikansi (sig.) $0.000<0.05$, maka dapat disimpulkan bahwa secara parsial variabel pengetahuan dan pemahaman wajib pajak berpengaruh positif dan signifikan terhadap variabel kepatuhan wajib pajak. 
2) Berdasarkan hasil uji t (parsial) pada model regresi, nilai signifikansi variabel kesadaran wajib pajak sebesar $0.039<0.05$ (taraf signifikansi 5\%). Selain itu dapat dilihat juga dari hasil perbandingan antara thitung dan ttabel yang menunjukkan nilai $\mathrm{t}_{\text {hitung }}$ sebesar 2.086, sedangkan $\mathrm{t}_{\text {tabel }}$ sebesar 1.65765. Dari hasil tersebut terlihat bahwa $t_{\text {hitung }}>t_{\text {tabel }}$ yaitu $2.086>1.65765$ dan nilai signifikansi (sig.) $0.039<0.05$, maka dapat disimpulkan bahwa secara parsial variabel kesadaran wajib pajak berpengaruh positif dan signifikan terhadap variabel kepatuhan wajib pajak.

3) Berdasarkan hasil uji t (parsial) pada model regresi, nilai signifikansi variabel sanksi pajak sebesar $0.009<0.05$ (taraf signifikansi 5\%). Selain itu dapat dilihat juga dari hasil perbandingan antara thitung dan ttabel yang menunjukkan nilai $\mathrm{t}_{\text {hitung }}$ sebesar 2.665, sedangkan $\mathrm{t}_{\text {tabel }}$ sebesar 1.65765. Dari hasil tersebut terlihat bahwa $t_{\text {hitung }}>\mathrm{t}_{\text {tabel }}$ yaitu $2.665>1.65765$ dan nilai signifikansi (sig.) $0.009<0.05$, maka dapat disimpulkan bahwa secara parsial variabel sanksi pajak berpengaruh positif dan signifikan terhadap variabel kepatuhan wajib pajak.

4) Berdasarkan hasil uji t (parsial) pada model regresi, nilai signifikansi variabel penghindaran pajak sebesar $0.010<0.05$ (taraf signifikansi 5\%). Selain itu dapat dilihat juga dari hasil perbandingan antara thitung dan ttabel yang menunjukkan nilai $t_{\text {hitung }}$ sebesar 2.606, sedangkan $t_{\text {tabel }}$ sebesar 1.65765. Dari hasil tersebut terlihat bahwa $\mathrm{t}_{\text {hitung }}>\mathrm{t}_{\text {tabel }}$ yaitu $2.606>1.65765$ dan nilai signifikansi (sig.) $0.010<0.05$, maka dapat disimpulkan bahwa secara parsial variabel penghindaran pajak berpengaruh positif dan signifikan terhadap variabel kepatuhan wajib pajak.

\section{SIMPULAN}

Berdasarkan hasil analisis terhadap data yang dikumpulkan, maka dapat diambil kesimpulan bahwa modernisasi Sistem Administrasi Perpajakan, berdasarkan hasil dari pengujian yang dilakukan maka modernisasi sistem administrasi perpajakan tidak berpengaruh erhadap kepatuhan wajib pajak. Pemahaman Peraturan Perpajakan, berdasarkan hasil dari pengujian yang dilakukan maka pemahaman peraturan perpajakan berpengaruh positif terhadap kepatuhan wajib pajak. Sanksi Perpajakan, berdasarkan hasil dari pengujian yang dilakukan maka sanksi perpajakan berpengaruh positif terhadap kepatuhan wajib pajak. Kualitas Pelayanan Fiskus, berdasarkan hasil dari pengujian yang dilakukan maka kualitas pelayanan fiskus berpengaruh positif terhadap kepatuhan wajib pajak.

Berdasarkan hasil penelitian, terdapat beberapa keterbatasan yang ada dalam penelitian ini adalah keterbatasan waktu dalam melakukan penelitian yang diberikan oleh pihak KPP. Responden dalam penelitian ini hanya wajib pajak badan, sehingga hasil analisis yang diperoleh hanya berlaku wajib pajak badan, tidak termasuk wajib pajak orang pribadi dan pengusaha kena pajak (PKP).

Berdasarkan simpulan yang dikemukakan maka hasil penelitian ini dapat digunakan baik untuk pengembangan teori secara lebih lanjut ataupun sebagai penerapan dalam praktik bisnis yang ada. Implikasi yang terdapat dalam penelitian ini antara lain diharapkan pemerintah dapat meningkatkan program administrasi perpajakan kepada masyarakat agar kepatuhan wajib pajak dapat meningkat. Pemahaman dan informasi yang di berikan oleh DJP kepada wajib pajak meningkan kepatuhan wajib pajak. Diharapkan dapat menjaga pengenaan sanksi pajak bagi wajib pajak yang melanggar agar meningkatkan kepatuhan wajib pajak. Kualitas pelayanan fiskus dari KPP Pratama Tambora memnerikan pengaruh terhadap kepatuhan wajib pajak 
Faktor-

Faktor yang

Mempengaruhi..

174

\section{DAFTAR PUSTAKA}

Adithya Febrian Arifin (2015). Pengaruh Modernisasi Sistem Administrasi Perpajakan, Kesadaran Perpajakan, Sanksi Pajak dan Pelayanan Fiskus Terhadap Kepatuhan Wajib Pajak Orang Pribadi pada KPP Pratama. Perbanas Review Vol.1, No.1

Albinus Boymau (2016). Pengaruh Modernisasi Sistem Administrasi Perpajakan dan Sanksi Pidana Terhadap Tingkat Kepatuhan Pengusaha Kena Pajak dengan Pemeriksaan Pajak Sebagai Variabel Moderating (Survey Pada Kawasan Industri Lippo Cikarang, Bekasi). Media Akuntansi Perpajakan Vol.1, No.2

Arifah, Rita Andini, dan Kharis Raharjo (2017). Pengaruh Modernisasi Sistem Administrasi Perpajakan, Kualitas Pelayanan, Pengetahuan Perpajakan, Sanksi Perpajakan dan Kesadaran Perpajakan Terhadap Kepatuhan Wajib Pajak Orang Pribadi pada Kantor Pelayanan Pajak Pratama Demak Selama Periode (2012-2016). Ekonomi - Akuntansi 2017 Universitas Pandanaran Semarang

Bayu Cakoro, Heru Susilo dan Zahroh Z.A (2015). pengaruh Pengetahuan Perpajakan, Kualitas Pelayanan Pajak dan Sanksi Pajak Terhadap Motivasi Wajib Pajak Orang Pribadi Dalam Membayar Pajak. Jurnal Perpajakan (JEJAK), Vol.1, No.1

Cindy Jotopurnomo dan Yenni Mangoting (2013). Pengaruh Kesadaran Wajib Pajak, Kualitas Pelayanan Fiskus, Sanksi Perpajakan, Lingkungan Wajib Pajak Berada terhadap Kepatuhan Wajib Pajak Orang Pribadi di Surabaya.Tax \& Accounting Reiew, Vol.1, No.1

I Putu Indra Pradnya Paramartha dan Ni Ketut Rasmini (2016). Pengaruh Kualitas Pelahyanan, Pengetahuan dan Sanksi Perpajakan pada Kepatuhan Wajib Pajak Badan. E-Jurnal Akuntansi Universitas Udayana Vol.15, No.1

Ismawati, Erlina. 2017. Pengaruh Pemahaman Peraturan Perpajakan, Kualitas Pelayanan Fiskus, Sanksi Pajak, dan Tax Amnesty terhadap Kepatuhan Wajib Pajak dengan Preferensi Risiko Sebagai Variabel Moderasi. Fakultas Ekonomi dan Bisnis Islam. Institut Agama Islam Negeri Surakarta.

Ikatan Akuntansi Indonesia. 2006. Modul Pelatihan Pajak Terapan Brevet AB Terpadu. Jakarta: Ikatan Akuntansi Indonesia.

Jelang Batas Waktu, Baru 23\% Wajib Pajak Badan yang Lapor SPT. https:// katadata.co.id/berita/2018/04/19/jelang-batas-waktu-baru-23-wajib-pajakbadan-yang-lapor-spt. (diakses 13 Mei 2018).

Keputusan Mentri Keuangan No. 235/KMK.03/2003 tanggal 3 juni 2003http:// www.ortax.org/ortax. (diakses 15 April 2018).

Mahfud, Muhammad Arfan, dan Syukriy Abdullah (2017). Pengaruh Pemahaman Peraturan Perpajakan, Kesadaran Memabayar Pajak dan Kualitas Pelayanan Perpajakan Terhadap Kepatuhan Wajib Pajak Badan (Studi Empiris pada Koperasi di Kota Banda Aceh). Jurnal Magister Akuntansi Pascasarjana Universitas Syiah Kuala Vol 6, No.2

Meiliyah Ariani, dan Tyas Erasari Utami (2016). Pengaruh Pelayanan Aparat Pajak, Modernisasi Sistem Administrasi Perpajakan dan Sanksi Pajak Terhadap Motivasi Wajib Pajak Orang Pribadi Dalam Membayar Pajak Penghasilan. Jurnal TEKUN/VOLUME VII, No.01

Pakpahan, Yunita Eriyanti. 2015. Pengaruh Pemahaman Akuntansi, Pemahaman Ketentuan Perpajakan, dan Transparansi dalam Pajak terhadap Kepatuhan Wajib Pajak Badan. JOM.FEKON, Vol. 2, No. 1.

Puji Rahayu, Anita Wijayanti, dan Suhendro (2017). Pengaruh Kesadaran Wajib Pajak, Pelayanan Fiskus, dan Sanksi Pajak Terhadap Kepatuhan Wajib Pajak Orang Pribadi. E-Jurnal Akuntansi Universitas Islam Batik Surakarta 
Putu Agustini Eka Pratiwi W, dan Ni Luh Supadmi (2016). Pengaruh Modernisasi Sistem Administrasi dan Sanksi Perpajakan Pada Kepatuhan Wajib Pajak. E-Jurnal Akuntansi Universitas Udayana Vol.15.

Rindi Lestari Suci Sofiyana, Djamhur Hamid, dan Muhammad Faisal Riza (2014). Pengaruh Modernisasi Sistem Administrasi Perpajakan Terhadap Tingkat Kepatuhan Wajib Pajak pada Kantor Pelayanan Pajak Pratama Batu.

Undang-Undang Republik Indonesia Nomor 28 Tahun 2007 tentang Perubahan Ketiga atas Undang-Undang Nomor 6 Tahun 1983 tentang Ketentuan Umum dan Tatacara Perpajakan (KUP)

Widya K Sarunan (2015). Pengaruh Modernisasi Sistem Administrasi Perpajakan Terhadap Kepatuhan Wajib Pajak Orang Pribadi dan Wajib Pajak Badan Pada Kantor Pelayanan Pajak Pratama Manado. Jurnal EMBA Vol.3 No.4 
